\title{
MECANISMOS DE DEFESA DA PROPRIEDADE: OFENDÍCULOS
}

Matheus Machado Guaberto, Danielle Yurie Moura da Silva

Universidade do Oeste Paulista, UNOESTE, Curso de Direito, Presidente Prudente, SP. E-mail: mmguaberto@gmail.com

\section{RESUMO}

Devido à crescente criminalidade que está insurgindo atualmente, muitas pessoas, preocupadas com os seus bens jurídicos, adotam medidas que visam preservar seus patrimônios e assegurá-los dentro do domicílio. Uma alternativa para essa preocupação é a instalação de ofendículos. Contudo, esses mecanismos devem ser utilizados de forma moderada e dentro dos limites legais. O Estado não dispõe de mecanismos suficientes e necessários para proteção à garantia dos direitos fundamentais, permitindo a este o uso de medidas preventivas para a segurança dos seus bens e integridade física, a base jurídica encontra-se no artigo 23 do Código Penal, onde engloba a utilização dos ofendículos, porém, não há um posicionamento sólido quanto à natureza jurídica destes artefatos. O método aplicado foi o dedutivo legal, baseado na interpretação da legislação, jurisprudências e doutrinas. Logo, ao analisar todos os posicionamentos, mostrou-se mais correto o que admite o uso como sendo um exercício regular de um direito.

Palavras-chave: Ofendículos. Artefatos de defesa. Bens jurídicos. Excesso.

\section{PROPERTY DEFENSE MECHANISMS: OFFENDICES}

\begin{abstract}
Due to the increasing crime that is currently rising, many people, concerned about their legal assets, adopt measures that aim to preserve their assets and ensure them within the home. An alternative to this concern is the installation of offending devices. However, these mechanisms should be used moderately and within legal limits. The State does not have sufficient and necessary mechanisms for the protection of the guarantee of fundamental rights, allowing it to use preventive measures for the security of its property and physical integrity. The legal basis is found in Article 23 of the Penal Code, which encompasses the use of offending, however, there is no solid position on the legal nature of these artifacts. The method applied was the legal deductive, based on the interpretation of the legislation, jurisprudence and doctrines. Therefore, when analyzing all the positions, it was more correct what admits the use as being a regular exercise of a right.
\end{abstract}

Keywords: Offenders. Defense artifacts. Legal goods. Excess. 


\section{INTRODUÇÃO}

O Estado tem a precípua função de garantir o bem-estar social, é um dever que engloba vários segmentos essenciais para a dignidade da pessoa humana, um deles é a garantia de segurança, um cidadão tem o direito de receber a proteção do Estado, não sendo apenas sobre sua vida, como também sobre os seus bens.

A segurança pública é dever do Estado e responsabilidade de todos, essa combinação permite-nos falar em uma maior efetividade para a preservação da ordem pública, tanto é que, o governo, por meio da polícia militar, adotou programas de policiamento comunitário para estreitar a relação com a comunidade, porém, na atual conjuntura, há também a necessidade de mudança da mentalidade com a restauração dos valores éticos e morais, tendo em vista que o registro de crimes e a população carcerária só aumentou no decorrer dos anos.

O Estado carece de mecanismos para garantir a proteção dos direitos fundamentais do cidadão, principalmente pelo fato da violência ser um problema crescente de caráter biopsicossocial, com isso, o ordenamento jurídico brasileiro, possibilita que o cidadão utilize medidas preventivas para proteger seus bens, tornando-se lícito repelir a força injusta pela justa.

A Constituição Federal, em seu artigo 50 inciso XXII, assegura a garantia do direito à propriedade, ou seja, abre margem para o cidadão tomar medidas cautelosas para a autotutela dos seus bens jurídicos, inclusive, no inciso XI, do mesmo artigo, prevê, como regra geral, que a casa é o asilo inviolável do indivíduo.

Com esse respaldo constitucional, para uma maior tranquilidade e segurança pessoal, algumas pessoas passaram a fazer uso dos ofendículos, termo proveniente da palavra offendiculum, que significa mecanismos de defesa da propriedade com o objetivo de dificultar e repelir uma possível agressão ao bem jurídico que se pretende resguardar, esses aparatos podem consistir na instalação de arames farpados, cacos de garrafa em muros, concertinas, eletrificações de grades e maçanetas, entre outros.

Os ofendículos têm proteção jurídica para a autodefesa baseada no artigo 23 do Código Penal Brasileiro que trata-se das excludentes de ilicitude, cuja finalidade é fazer com que a conduta do agente se torne atípica de acordo com alguns requisitos, ou seja, esses mecanismos de defesa são lícitos, visto que tratam de medidas de proteção contra ofensas futuras e incertas, que só funcionarão no momento do ataque, devendo ser utilizados de forma moderada e proporcional ao agressor, pois, se ocorrer o excesso, o agente responderá por crime, seja na modalidade culposa ou dolosa.

Importante deixar claro que os ofendículos são instrumentos facilmente identificáveis, onde, no local de sua instalação, haverá placas de identificação e advertência, diferentemente das defesas mecânicas, que são instrumentos ocultos e de difícil percepção que geralmente configuram excesso de defesa.

O Artigo tem como objetivo explanar o conteúdo sobre o uso correto dos ofendículos, apresentar alguns entendimentos doutrinários sobre a natureza jurídica desses artefatos, bem como demonstrar que a simples proteção de um bem particular pode acarretar um excesso na conduta preventiva e uma eventual tipificação penal.

\section{METODOLOGIA}

O presente trabalho empregou pesquisas à legislação nacional, jurisprudências e doutrinas relevantes na matéria objeto de estudo. Foi empregado o método dedutivo para sistematizar os dados coletados a fim de cumprir o objetivo proposto. 


\section{OFENDÍCULO - EXERCíCIO REGULAR DE DIREITO.}

Trata-se aqui da existência de um direito garantido pelo Estado, de forma que a atuação dentro dos limites legais não pode ser considerada antijurídica, quem está autorizado a praticar um ato em consonância com a ordem jurídica como o exercício de um direito, age licitamente.

Segundo Graf Zu Dohna (Apud Toledo, 1994, p. 213), "Uma ação juridicamente permitida não pode ser ao mesmo tempo proibida pelo direito. Ou, em outras palavras, o exercício de um direito nunca é antijurídico".

O cidadão, ao fazer uso dos ofendículos, visa tão somente à prevenção contra uma possível agressão futura, exerce o direito de defesa da propriedade que está garantido no Código Civil, Artigo 1.210, §1ㅇ “O possuidor turbado, ou esbulhado, poderá manter-se ou restituir-se por sua própria força, contanto que o faça logo; os atos de defesa, ou de desforço, não podem ir além do indispensável à manutenção, ou restituição da posse".

Nesse sentido, Aníbal Bruno (Apud Capez, 2017, p 314):

Não nos parece que a hipótese possa ser resolvida como legítima defesa [...] embora o aparelho só se destine a funcionar no momento do ataque, a verdadeira ação do sujeito é anterior: no momento da agressão, quando cabia a reação individual, ele, com o seu gesto e a sua vontade de defesa, está ausente. Além disso, a atuação do aparelho é automática e uniforme, não pode ser graduada segundo a realidade e a importância do ataque [...] Por tudo isso, esse proceder fica distante dos termos precisos da legítima defesa, que supõe sempre um sujeito atuando, com o seu gesto e o seu ânimo de defender-se, no mesmo momento e com a medida justa e oportuna contra a agressão atual ou iminente.

Essa causa de exclusão de ilicitude, assim como todas as demais, deve obedecer aos limites legais. Quem tem um direito, dele não pode abusar. O excesso ou abuso enseja, além do afastamento da excludente, a utilização da legítima defesa por parte do prejudicado pelo exercício irregular e abusivo do direito.

\section{OFENDÍCULO - LEGÍTIMA DEFESA PREORDENADA.}

É o tipo de defesa que atua somente no momento da agressão injusta, atual e iminente do bem jurídico tutelado, bem como a utilização deste obstáculo deve ser de forma proporcional e moderada, de tal forma, presente esses requisitos, será excluída a antijuricidade, esse é o argumento dos defensores da ideia que o uso dos ofendículos caracteriza-se como legítima defesa preordenada.

Nelson Hungria (1978, p. 294) um dos expoentes dessa doutrina, preconiza que aquele que predispõe o ofendículo "não se encontra em condição diversa daquele que se arma de uma espingarda ou adquire um cão de guarda, prevendo a eventualidade de um assalto", ainda afirma que "pouco importa que a instalação do aparelho insidioso preceda ao momento da agressão, desde que só entra em funcionamento na ocasião em que o perigo se faz atual".

Conforme Gracieli Firmino da Silva (2006, p. 82):

A simples instalação de um obstáculo de proteção de um bem jurídico não gera consequência no mundo fático. Com efeito, no instante em que o bem protegido é ameaçado, efetivamente o ofendículo entra em funcionamento. Neste instante surge para o cenário jurídico, uma agressão injusta passível de uma defesa lícita.

Existe a legítima defesa porque o aparato só funcionará quando houver agressão, e é preordenada porque foi posta anteriormente a esta.

Ainda segundo o doutrinador Nelson Hungria (1978, p.295):

Pode acontecer, entretanto, uma aberratio in persona, isto é, que ao invés do ladrão, venha a ser vítima da armadilha uma pessoa inocente. A hipótese deve ser tratada como legítima defesa putativa, posto que se comprove que o proprietário ou ocupante da casa estava persuadido de que a armadilha somente poderia colher o fur nocturnu: se foram 
tomadas as precauções devidas para que o aparelho não fosse infiel à sua finalidade, o evento lesivo contra alia persona não deixa de ser antijurídico, mas não pode ser imputado, nem mesmo a título de culpa.

Como exemplo, temos o caso de quando uma criança se fere com cacos de vidro colocados em cima de um muro, porque foi buscar uma pipa presa na árvore. Nesse caso, o autor poderá invocar a legítima defesa putativa.

Cabe salientar que a putatividade contida na legítima defesa deve ser analisada e julgada de acordo com a conduta do agente no caso concreto, não raras vezes, pode ocorrer o erro de proibição indireto, que é uma causa de exclusão da ilicitude imaginada pelo agente em razão de uma equivocada consideração dos limites autorizados pela justificadora, ou seja, o indivíduo sabe da norma proibitiva, porém acredita que sua atitude tem uma justificativa e não estará incorrendo em crime, nesse caso temos duas possibilidades, se o erro cometido pelo agente for escusável e ficar caracterizado a inexigibilidade de conduta diversa, será excluída a culpabilidade, portanto, ficará isento da pena e receberá absolvição própria, em contrapartida, se o erro for vencível e fosse possível exigir uma conduta diversa, o agente será punido pelo excesso, porém, com causa de diminuição da pena. A legítima defesa real exclui a antijuricidade, já a legítima defesa putativa recai diretamente sobre a culpabilidade.

\section{OFENDÍCULOS - TEORIA HÍBRIDA}

$\mathrm{Na}$ teoria híbrida ocorre uma posição intermediária, onde a natureza jurídica dos ofendículos é tratada tanto como exercício regular de direito como legítima defesa preordenada, o que vai definir é o momento da instalação e o seu efetivo funcionamento.

Cezar Roberto Bitencourt (2017, p. 444) defende que "a decisão de instalar os ofendículos constitui 'exercício regular de direito', isto é, exercício do direito de auto proteger-se. No entanto, quando reage ao ataque esperado, inegavelmente, constitui legítima defesa preordenada".

\section{ALCANCE DOS OFENDÍCULOS E EXCESSO PUNÍVEL}

Cabe destacar que há dois tipos de ofendículos, um trata-se de aparelhos e engenhos produzidos pelo homem, permitindo um controle e uma regulagem mais eficiente por parte do proprietário, e o outro que são os animais, mais especificamente os cães de guarda, cujo proprietário tem menor controle, tendo em vista serem seres vivos, que atuam por instintos e preservação, tanto da sua vida, como do território em que habita.

Em relação aos aparatos produzidos pelo homem, é de suma importância que seja observado os requisitos de moderação e proporcionalidade, tendo em vista que podem ocorrer algumas adversidades, no momento da instalação deve atentar-se apenas para a proteção da vida e do bem jurídico, escusando-se de sentimentos hostis e agressivos para não exacerbar na defesa no momento da injusta agressão.

Caso típico e de fácil percepção de excesso na utilização dos ofendículos é quanto à voltagem utilizada em cercas eletrificadas, onde, se o proprietário valer-se de uma voltagem maior do que a permitida, com o intuito de causar a morte do invasor assim que ele a toque, certamente incorrerá em excesso e será penalizado penalmente, seja por dolo ou culpa, caso contrário, se o proprietário utilizar uma voltagem em conformidade com as normas da Associação Brasileira de Normas Técnicas (ABNT) e com as devidas identificações, no ato em que o infrator estiver praticando a ilicitude penal, resvalar-se na cerca e com a queda falecer, tratar-se-á de caso fortuito, estando o proprietário nitidamente amparado pela excludente de ilicitude.

Outro aspecto importante é quanto aos animais que têm a função de proteger a propriedade, deve-se observar alguns requisitos e cuidados para evitar a reversão na injusta agressão, visto que não há regulagem e total controle do proprietário. 
Portanto, se um invasor for atacado por cães e morrer em virtude das lesões, trata-se de caso fortuito, desde que, o animal, esteja em área não acessível ao público legitimado para frequentar o lugar, no mesmo raciocínio encontra o invasor que, no período noturno, invade propriedade alheia para a prática de qualquer atividade e acaba sendo atacado por cães que protegem por instinto o seu espaço, nesses dois casos há proteção das excludentes de ilicitude para o possuidor da propriedade.

Por outro lado, o proprietário do animal não poderá treiná-lo para ataques fulminantes, pois isto seria o mesmo que preparar uma cerca elétrica para matar eletrocutado o invasor, bem como, não pode utilizar-se de animais diferenciados na proteção de sua propriedade, como felinos selvagens e cobras venenosas, se assim o fizer, teremos a imoderação do ofendículo, uma vez que a possibilidade de controle torna-se ainda menor, configurando-se um excesso de defesa.

Cabe salientar que a responsabilidade civil no caso de ataque de cães ou outros animais é objetiva, conforme o texto do Artigo 936 do Código Civil "O dono, ou detentor, do animal ressarcirá o dano por este causado, se não provar culpa da vítima ou força maior".

Como dito anteriormente o Artigo 23 do Código Penal trata-se das excludentes de ilicitude e o seu parágrafo único tem a seguinte redação "O agente, em qualquer das hipóteses deste artigo, respondera pelo excesso doloso ou culposo".

\section{CONCLUSÃO}

O Estado tem o dever de garantir a segurança e o bem-estar da sua população, como também a preservação dos patrimônios públicos particulares, porém, detentores de uma Constituição analítica, nosso ordenamento jurídico prevê alguns empreendimentos que o indivíduo pode adotar para aumentar a proteção de sua propriedade e consequentemente sua vida, obviamente que dentro dos limites e proporções razoáveis.

Trata-se de um artefato importante tanto na esfera da segurança quanto na seara jurídica, onde, devido à necessidade real frente à ação de delinquentes, sua utilização está cada vez mais frequente, tanto é que, não raramente, em algumas propriedades, esses objetos são caseiros, feitos pelo próprio dono, a fim de garantir a sensação de segurança por um melhor custobenefício, cabe salientar que no momento da instalação deve-se atentar para as normas vigentes, protegendo-se em conformidade com a lei esquiva-se de irresponsabilidades futuras.

Com isso, conclui-se que os ofendículos instalados de forma correta possuem amparo no Código Penal e retiram a ilicitude do fato típico, um dos requisitos do crime.

$\mathrm{O}$ artigo tem a finalidade de atrair a atenção, tanto dos possuidores desse artefato, quanto dos profissionais que o instalam, para saberem como se defender e evitarem imprevistos envolvendo os ofendículos, vale ressaltar que, respeitando o posicionamento dos doutrinadores, a natureza jurídica do ofendículo, como corrente majoritária, enquadra-se melhor como exercício regular de um direito, haja vista a impossibilidade de moderação no momento do funcionamento e o subjetivismo da injusta agressão quando atingir um inocente, fatores que excluem os requisitos da legítima defesa.

\section{REFERÊNCIAS}

ATLAS, E. Código Civil - Lei no 10.406, de 10-1-2002. 7 ed. Atlas, 2012.

BITENCOURT, C. R. Tratado de Direito Penal. v.1. 23 ed. Editora Saraiva, 2017.

BRASIL. Constituição (1988). Constituição da República Federativa do Brasil. Brasília, DF: Senado Federal, 1988.

CAPEZ, F. Curso de Direito Penal. v.1. 21 ed. Editora Saraiva, 2017. 
BRASIL. Código Penal: Decreto-lei n. 2.848, de 7 de dezembro de 1940. Editoria Jurídica da Editora M. 2nd edição: Manole, 01/2017.

HUNGRIA, N. Comentários ao Código Penal. v.1. 5 ed. Rio de Janeiro: Forense, 1978.

NUCCI, G. S. Manual de Direito Penal. 13 ed. Forense, 2017.

SILVA, G. F. D. Ofendículos e suas implicações no direito penal brasileiro. 2006. 158 f. Dissertação (Mestrado em Direito) - Pontifícia Universidade Católica de São Paulo, São Paulo, 2006.

TOLEDO, F. D. A. Princípios Básicos de Direito Penal. 5 ed. São Paulo: Saraiva, 1994. 